\title{
Soft Tissue Cephalometric Norms for Bihar Ethnic Population
}

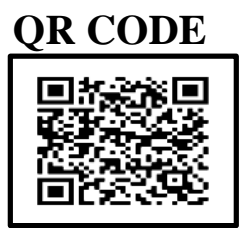

\section{RAHUL MUNKA, VAIBHAV SHANDILYA*1, HARSH KUMAR², ABHISHEK SINHA²}

INTRODUCTION: A person's ability to recognize a beautiful face is innate, but translating this into defined treatment goals is problematic and various authors tried to relate the importance of soft-tissue esthetics with orthodontic diagnosis and treatment planning.

AIM AND OBJECTIVES: To derive the Soft Tissue Cephalometric norms for the normal, well-balanced and esthetically pleasing faces of the Bihar ethnic population and to compare them with pre-established norms.

MATERIALS AND METHOD: A sample of 60 subjects from an ethnic Bihar population residing in Patna, on the basis of facial symmetry, balance and pleasing appearance were observed from five sets of extra-oral photographs. Standardized lateral cephalometric radiographs were taken with metallic markers placed on various soft-tissue structures on the face using derma tapes. All lateral cephalometric films were traced and Soft Tissue Cephalometric Analysis was done.

RESULTS: Total facial length was significantly less in males as compared to the Caucasians with $117.50 \pm 1.74$ as mean value. Males had significantly less protrusive upper and lower lips in projection to TVL with a mean value of $0.77 \pm 0.77$ and $-3.13 \pm 0.73$ respectively. Lower lip length in females was significantly decreased with a decreased lower third facial height with a mean value of $62.27 \pm 1.46$. Total facial length was significantly less in females with a mean value of $115.40 \pm 1.99$. Females had significantly more protrusive upper and lower lips in projection to TVL with a mean value of $1.90 \pm 0.84$ and $1.93 \pm 0.74$ respectively. CONCLUSION: The established norms in present study could be used as future reference for Orthodontic treatment in Bihar ethnic population.

KEYWORDS: Soft Tissue analysis, Soft-Tissue Cephalometric Analysis ( STCA), cephalometric analysis, Arnett \& Bergmann, True Vertical Line (TVL)

\section{INTRODUCTION}

A person's ability to recognize a beautiful face is innate, but translating this into defined treatment goals is problematic. Various authors have tried to relate the importance of soft-tissue esthetics with orthodontic diagnosis and treatment planning.

Arnett and Bergman ${ }^{1,2}$ presented the Facial Keys to Orthodontic Diagnosis and Treatment Planning as a three-dimensional clinical blueprint for soft tissue analysis and treatment planning. Later, they developed the Soft-Tissue Cephalometric Analysis (STCA) ${ }^{3}$ for orthodontic diagnosis and treatment planning. Analysis of dental and skeletal patterns alone might be inadequate or misleading, because of marked variations in the soft tissues covering the dentoskeletal framework. ${ }^{4}$

Richardson 5 (1980) defined the term "ethnic group" as a "nation or population with a common bond such as geographical boundary, a culture or language, or being racially or historically related".

However, there has been no conclusive investigation in this matter undertaken on the people of Bihar, a part of the India, which has a distinct facial and physical characteristics with distinct lifestyle and culture of their own.

The purpose of the present study is to derive the Soft Tissue Cephalometric norms for the normal, wellbalanced and esthetically pleasing faces of the Bihar ethnic population, which will be useful in providing clinically specific values for diagnosis and treatment planning.

\section{MATERIAL AND METHODS}

Subject Selection: The sample of Eighty young adults (40 males and 40 females) was selected from an ethnic Bihar population residing in the area of Patna, Bihar.

A composite of male and female subjects [Figure 1 (a) \& (b)] were prepared and they were then rated for facial symmetry, balance and pleasing appearance by a panel of five judges including an orthodontist, an oral surgeon, an endodontist, a prosthodontist and a social worker. The judges, after screening the subjects, selected sixty subjects (30 males and 30 females), on which the study was then carried out.

The inclusion criteria were the ethnicity i.e. at least 3 

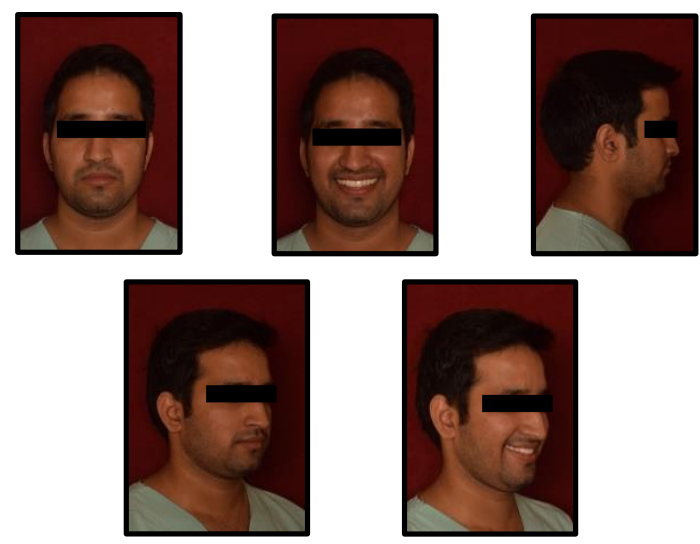

Figure 1 (a). Composite Extra Oral Photographs of a Male Subject

generations should have been residing in Patna, young adults with Class I occlusion, well-balanced facial profile, full complement of permanent teeth, normal overjet (2-3mm) and normal overbite (2-3mm) and mild crowding or spacing $(\leq 3 \mathrm{~mm})$, mild rotations are considered as acceptable. The exclusion criteria were marked facial asymmetry, history of previous orthodontic treatment, craniofacial deformities, history of facial or systemic pathologies, history of trauma.

Data Collection: Five sets of extra oral photographs were taken with a DSLR camera for each subject in 5 different views i.e. frontal rest, frontal smiling, profile, oblique rest, oblique smiling [Figure 1 (a \& b)]. Subjects were selected and standardized lateral cephalometric radiographs were taken in natural head position6. Metallic markers measuring $1 \mathrm{~mm}$ in diameter were placed on various soft-tissue structures on the faces with the help of derma tapes.

Landmarks identified by Metal Markers (Figure 2)

1. Orbital rim: placed directly over the osseous orbital rim and directly under the pupil with the eye in straight-ahead gaze.

2. Cheekbone: the right most malar prominence of the contour in three quarter view.

3. Alar base: placed in the deepest depression at the alar base of the nose.

4. Subpupil: directly below the straight ahead gaze of the pupil i.e one half the vertical distance between the orbital rim and alar base markers.

5. Neck-throat point: the intersection between the throat and neck.

All lateral cephalometric films were traced by two operators in a standardized manner to eliminate bias in
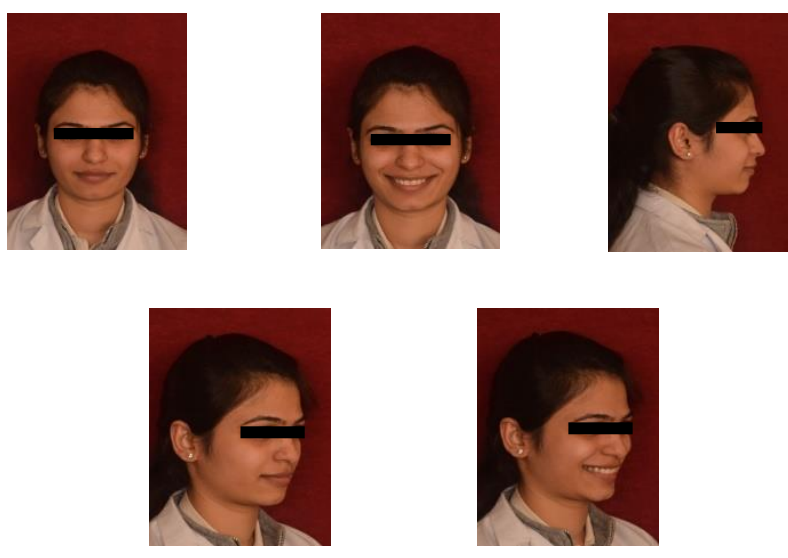

Figure 1 (b). Composite Extra Oral Photographs of a Female Subject

the study. The landmarks and measurements were taken according to the Soft Tissue Cephalometric Analysis (STCA) ${ }^{3}$, which was studied and related to the True Vertical Line (TVL) as described by Arnett et al.,

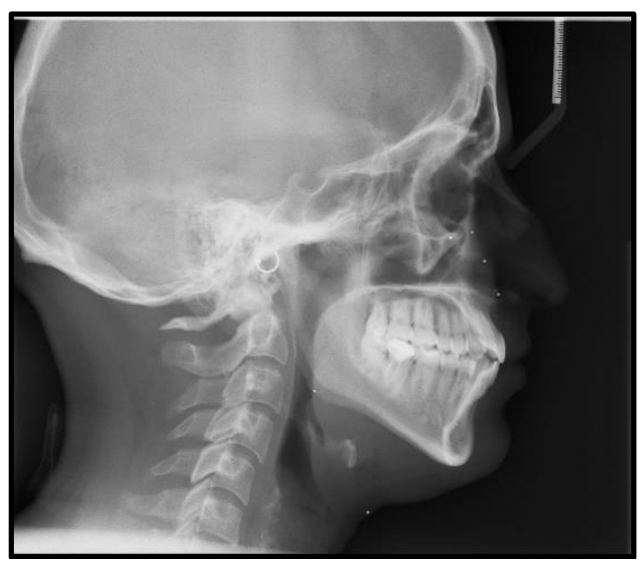

Figure 2. Lateral Cephalogram with Metallic Markers

Statistical Analysis: Normality of the data was checked by Shapiro Wilk test. Data failed to achieve normality. Thus, inferential statistics were performed using non-parametric tests of significance. Inferential statistics were performed using Mann Whitney U test. The level of statistical significance was set at 0.05 .

\section{RESULTS}

Descriptive statistics and the results of Soft tissue Cephalometric analysis comparison between Subject males and Caucasian males (Table 1 )

The total facial length from soft tissue nasion to menton is significantly less than the Caucasians with a mean value of $117.50 \pm 1.74$. The upper and lower lip length is 


\begin{tabular}{|c|c|c|c|c|}
\hline \multirow[t]{2}{*}{ Measurements } & \multicolumn{2}{|c|}{ Males (Subjects) } & \multicolumn{2}{|c|}{ Males (Caucasians) } \\
\hline & Mean & SD & Mean & SD \\
\hline \multicolumn{5}{|l|}{ DENTOSKELETAL FACTORS } \\
\hline Mxı to Occlusal Plane & 56.83 & 2.17 & 57.8 & 3.00 \\
\hline Md1 to Occlusal Plane & 62.57 & 1.45 & 64.0 & 4.00 \\
\hline Overjet & 3.23 & 1.10 & 3.2 & 0.6 \\
\hline Overbite & 2.80 & 0.89 & 3.2 & 0.7 \\
\hline \multicolumn{5}{|l|}{ SOFT TISSUE STRUCTURES } \\
\hline Upper Lip Thickness & 9.17 & 1.53 & 14.8 & 1.4 \\
\hline Lower Lip Thickness & 12.33 & 1.84 & 15.1 & 1.2 \\
\hline Pogonion - Pogonion' & 14.07 & 2.92 & 13.5 & 2.3 \\
\hline Menton - Menton' & 11.10 & 1.47 & 8.8 & 1.3 \\
\hline Nasolabial Angle & 103.63 & 2.46 & 106.4 & $7 \cdot 7$ \\
\hline Upper Lip Angle & 9.63 & 2.27 & 8.3 & $5 \cdot 4$ \\
\hline \multicolumn{5}{|l|}{ FACIAL LENGTH } \\
\hline Nasion' - Menton' & $117 \cdot 50$ & 1.74 & $137 \cdot 7$ & 6.55 \\
\hline Upper Lip Length & 20.57 & 1.89 & $24 \cdot 4$ & 2.5 \\
\hline Interlabial Gap & 0.73 & 0.83 & 2.4 & 1.1 \\
\hline Lower Lip Length & 44.67 & 1.79 & $54 \cdot 3$ & 2.4 \\
\hline Lower $1 / 3$ of the face & $65 \cdot 53$ & 2.89 & 81.1 & $4 \cdot 7$ \\
\hline Overbite & 2.80 & 0.89 & 3.2 & 0.7 \\
\hline Mxi exposure & 0.73 & 0.83 & $3 \cdot 9$ & 1.2 \\
\hline Maxillary Height & $24 \cdot 77$ & 2.50 & 28.4 & 3.2 \\
\hline Mandibular Height & 46.00 & 1.49 & 56.0 & 3.0 \\
\hline \multicolumn{5}{|l|}{ PROJECTION TO TVL } \\
\hline Glabella & -8.30 & 3.98 & -8.0 & 2.5 \\
\hline Nasal Projection & $14 \cdot 37$ & 1.16 & $17 \cdot 4$ & 1.7 \\
\hline Subnasale & 0.00 & 0.00 & o & o \\
\hline A Point' & -2.87 & 0.86 & -0.3 & 1.0 \\
\hline Upper Lip Anterior & 0.77 & 0.77 & $3 \cdot 3$ & 1.7 \\
\hline $\mathbf{M x ı}$ & $-13 \cdot 50$ & 1.14 & -12.1 & 1.8 \\
\hline Md1 & -15.83 & 1.23 & $-15 \cdot 4$ & 1.9 \\
\hline Lower Lip Anterior & -3.13 & 0.73 & 1.0 & 2.2 \\
\hline B Point' & -10.77 & 1.52 & -7.1 & 1.6 \\
\hline Pogonion' & -5.0 & 1.2 & $-3 \cdot 5$ & 1.8 \\
\hline \multicolumn{5}{|l|}{ ADDITIONAL POINTS } \\
\hline Orbitale & -23.70 & 1.39 & -22.4 & 2.7 \\
\hline Cheekbone & -30.70 & $3 \cdot 70$ & -25.2 & 4.0 \\
\hline
\end{tabular}




\begin{tabular}{|c|c|c|c|c|}
\hline Ala of the nose & -15.87 & 1.55 & -15.0 & 1.7 \\
\hline Subpupil & -20.133 & 0.819 & -18.4 \\
\hline Angle of Mandible & -90.223 & 2.873 & 1.9 \\
\hline Chin - Throat Angle & -58.433 & 2.487 & \\
\hline
\end{tabular}

Table 1. Descriptive statistics and the results of Soft tissue Cephalometric analysis comparison between Subject males and Caucasian males

also significantly decreased with a significant less lower third facial height, mean value of $65.53 \pm 2.89$. Upper and lower lip thickness of the male population is significantly less than the Caucasians with a mean value of $9.17 \pm 1.53$ and $12.33 \pm 1.84$ respectively. The subject males have significantly less protrusive upper and lower lips in projection to TVL with a mean value of $0.77 \pm 0.77$ and $-3.13 \pm 0.73$ respectively. The Maxillary dentition is significantly retrusive with soft tissue A point and B point also being retrusive in projection to TVL with a mean value of $-2.87 \pm 0.86$ and $-10.77 \pm 1.52$. The orbitale, cheekbone, ala of the nose and subpupil are significantly retropositioned in projection to TVL with the mean values of $-23.70 \pm 1.39,-30.7 \pm 3.7,-15.87 \pm 1.55$ and $-20.13 \pm 0.819$ respectively.

Descriptive statistics and the results of Soft tissue Cephalometric analysis comparison between Subject females and Caucasian females (Table 2)

The total facial length from soft tissue nasion to menton is significantly less than the Caucasians with a mean value of $115.40 \pm 1.99$. The lower lip length is also significantly decreased with a significantly less lower third facial height with a mean value of $62.27 \pm 1.46$. third facial height of females is significantly less than males with a mean value of $62.27 \pm 1.46$. Lower lip thickness in the females population is significantly less than the males with a mean value of $10.03 \pm 0.81$ and $12.33 \pm 1.84$ respectively. The females have significantly more protrusive upper and lower lips in projection to TVL with a mean value of $1.90 \pm 0.84$ and $1.93 \pm 0.74$ respectively. The orbitale, ala of the nose, subpupil and angle of the mandible are significantly retropositioned in the male population when compared to females whereas the cheekbone and the point at the chin throat angle are retropositioned in the female population when compared to the male population.

\section{DISCUSSION}

The STCA uses True Vertical Line (TVL) ${ }^{4}$ which is a completely different reference in comparison to the other soft tissue analysis. The TVL eliminates the problems associated with cranial base cephalometry as
Upper and lower lip thickness of the female subjects is significantly less than the Caucasians with a mean value of $8.83 \pm 0.87$ and $10.03 \pm 0.81$ respectively. The females have significantly less protrusive upper lip in projection to TVL with a mean value of $1.90 \pm 0.84$ and also the upper lip angle of $7.97 \pm 1.67$. The maxillary and mandibular dentition is significantly retrusive with soft tissue $\mathrm{A}$ and $\mathrm{B}$ point also being retrusive in projection to TVL with a mean value of $-2.87 \pm 0.86$ and $-11.53 \pm 1.76$. The orbitale, ala of the nose and subpupil are significantly anteriorly positioned in projection to TVL with the means of $-17 \pm 0.74,-11.8 \pm 1.3$ and $-14.3 \pm 1.18$ respectively and the cheekbone is significantly retropositioned with a mean value of $-34 \cdot 17 \pm 1.39$.

Descriptive statistics and the results of Soft Tissue Cephalometric analysis comparison between Subject males and females (Table 3 )

The total facial length from soft tissue nasion to menton is significantly less in females than the males with a mean value of $115.40 \pm 1.99$. The lower lip length is significantly less in females than in males with the means of $41 \pm 0.91$ and $44.67 \pm 1.79$ respectively. The lower

it does not use the cranial base landmarks and has the maximum reliability and accuracy as it does not change with the minor errors of the cephalograms. Also, the TVL does not rely on any of the cephalometric landmark which could easily get altered by the head positions of different individuals.

In the male and female population, the upper and lower lip thickness is reduced when compared to the Caucasians. Both the sexes also have an increase in the thickness of soft tissue chin in the vertical plane. These results are in accordance with the study conducted by Tancansan Uysal et al. ${ }^{7}$ in Turkish adults which concluded that the lower lip thickness of the Turkish population was lower and menton thickness was greater than Arnett's norms. Also, in a study by Faruk Ayhan Basciftci et al. ${ }^{8}$ on Anatolian Turkish adults, it was reported that the Turkish men have greater upper lip thickness than the Turkish females. 


\begin{tabular}{|c|c|c|c|c|}
\hline & Mean & SD & Mean & SD \\
\hline \multicolumn{5}{|l|}{ DENTOSKELETAL FACTORS } \\
\hline Mxı to Occlusal Plane & 61.57 & 2.47 & 56.8 & 2.5 \\
\hline Mdi to Occlusal Plane & 63.83 & 4.28 & $64 \cdot 3$ & 3.2 \\
\hline Overjet & 2.93 & 0.83 & 3.2 & 0.4 \\
\hline Overbite & 3.47 & 1.14 & 3.2 & 0.7 \\
\hline \multicolumn{5}{|l|}{ SOFT TISSUE STRUCTURES } \\
\hline Upper Lip Thickness & 8.83 & 0.87 & 12.6 & 1.8 \\
\hline Lower Lip Thickness & 10.03 & 0.81 & 13.6 & 1.4 \\
\hline Pogonion - Pogonion' & 12.00 & 1.46 & 11.8 & 1.5 \\
\hline Menton - Menton' & 8.33 & 1.12 & $7 \cdot 4$ & 1.6 \\
\hline Nasolabial Angle & 101.30 & 3.56 & $103 \cdot 5$ & 6.8 \\
\hline Upper Lip Angle & $7 \cdot 97$ & 1.67 & 12.1 & 5.1 \\
\hline \multicolumn{5}{|l|}{ FACIAL LENGTH } \\
\hline Nasion' - Menton' & 115.40 & 1.99 & 124.6 & $4 \cdot 7$ \\
\hline Upper Lip Length & 20.77 & 1.50 & 21.0 & 1.9 \\
\hline Interlabial Gap & 0.73 & 0.78 & $3 \cdot 3$ & 1.3 \\
\hline Lower Lip Length & 41.00 & 0.91 & 46.9 & 2.3 \\
\hline Lower $1 / 3$ of the face & 62.27 & 1.46 & 71.1 & $3 \cdot 5$ \\
\hline Overbite & 3.47 & 1.14 & 3.2 & 0.7 \\
\hline Mxı exposure & 0.73 & 0.78 & $4 \cdot 7$ & 1.6 \\
\hline Maxillary Height & 24.13 & 1.59 & $25 \cdot 7$ & 2.1 \\
\hline Mandibular Height & 40.50 & 1.72 & 48.6 & 2.4 \\
\hline \multicolumn{5}{|l|}{ PROJECTION TO TVL } \\
\hline Glabella & $-7 \cdot 43$ & 1.79 & -8.5 & 2.5 \\
\hline Nasal Projection & $14 \cdot 37$ & 1.13 & 16.0 & 1.4 \\
\hline Subnasale & 0.00 & 0.00 & o & 0.00 \\
\hline A Point' & -2.87 & 0.86 & -0.1 & 1.0 \\
\hline Upper Lip Anterior & 1.90 & 0.84 & $3 \cdot 7$ & 1. 2 \\
\hline
\end{tabular}




\begin{tabular}{|c|c|c|c|c|}
\hline Mxi & -12.57 & 1.87 & -9.2 & 2.2 \\
\hline Mdi & -14.87 & 1.68 & -12.4 & 2.2 \\
\hline Lower Lip Anterior & -1.93 & 0.74 & 1.9 & 1.4 \\
\hline B Point' & -11.53 & 1.76 & -5.3 & 1.5 \\
\hline Pogonion' & -5.4 & 1.1 & -2.6 & 1.9 \\
\hline ADDITIONAL POINTS & & & \\
\hline Orbitale & & -18.7 & 2.0 \\
\hline Cheekbone & -17.00 & 0.74 & -20.6 & 2.4 \\
\hline Ala of the nose & -34.17 & 1.39 & 1.1 \\
\hline Subpupil & -11.80 & 1.30 & -12.9 & 2.1 \\
\hline Angle of Mandible & -14.367 & 1.188 & -14.8 & \\
\hline Chin - Throat Angle & -82.900 & 1.583 & & \\
\hline
\end{tabular}

Table 2. Descriptive statistics and the results of Soft tissue Cephalometric analysis comparison between Subject females and Caucasian females

Males had an increased facial height, lower $3^{\text {rd }}$ facial length and an increased lower lip length when compared to the female subjects. Contradicting these results, in a study conducted on Central India population of Madhya Pradesh by Rohit Yadav and Jyoti Singh,, it was concluded that the central India group exhibited a significantly increased lower third of face with greater convex profile, increased maxillary prognathism and increased facial convexity. Whereas, in another study on Turkish adults by Tancansan Uysal. ${ }^{7}$, it was concluded that soft tissue thicknesses were greater and facial lengths were longer in Turkish males than females, but the males had decreased upper incisor exposure when compared to Turkish females.

Similar observation was seen in a study by Kalha AS et al. ${ }^{4}$ on South Indian ethnic population which stated that facial height, upper lip length, lower lip length, lower third of the face and mandibular height were greater in men than in women. Similar to the soft tissue norms, hard tissue norms were also developed for orthognathic population in Karnataka population by $\mathrm{G}$ M Shashikumar ${ }^{10}$ which concluded that the subjects have greater upper posterior facial height and decreased lower anterior face height when compared to the Caucasians.

According to a study performed in Andhra Population by Lalitha $\mathrm{C}$ et al.," it was concluded that the males had a more acute nasolabial angle than the females with thicker, shorter and protrusive lips in both males and female subjects when compared to the Caucasians. Conversely, a study performed on South Indian population by Anmol S Kalha ${ }^{4}$, it was stated that the females have a greater interlabial gap and maxillary incisor exposure as compared to males. Also, in a study on Adolescent Kuwaitis by Rashed Al-Azemi ${ }^{12}$, it was observed that the Kuwaitis had increased incisors protrusion when compared to the Caucasians. Similarly, according to a study conducted by Scheideman ${ }^{13}$ the mandibular height was greater in men than in women.

A study done by Faruk Ayhan Basciftci ${ }^{8}$ on Anatolian Turkish adults, it was seen that the males had relatively prominent nose and soft tissue chin compared to the females. Conversely, a study done by Lalitha $\mathrm{C}$ et al." in Andhra population, concluded that mildly proclined incisors, mild facial convexity and retruded lower faces were considered as normal in the Indian population groups. According to Scheideman ${ }^{13}$, the nasal prominence was greater in men than in women. In a study conducted on Karnataka population by G M Shashikumar ${ }^{10}$ to establish hard tissue norms, it was observed that they have greater maxillary skeletal prognathism with increased lower incisor proclination 


\begin{tabular}{|c|c|c|c|c|}
\hline \multirow[t]{2}{*}{ Measurements } & \multicolumn{2}{|c|}{ Males } & \multicolumn{2}{|c|}{ Females } \\
\hline & Mean & SD & Mean & SD \\
\hline \multicolumn{5}{|l|}{ DENTOSKELETAL FACTORS } \\
\hline Mxi to Occlusal Plane & 56.83 & 2.17 & 61.57 & 2.47 \\
\hline Mdi to Occlusal Plane & 62.57 & 1.45 & 63.83 & 4.28 \\
\hline Overjet & 3.23 & 1.10 & 2.93 & 0.83 \\
\hline Overbite & 2.80 & 0.89 & 3.47 & 1.14 \\
\hline \multicolumn{5}{|l|}{ SOFT TISSUE STRUCTURES } \\
\hline Upper Lip Thickness & 9.17 & 1.53 & 8.83 & 0.87 \\
\hline Lower Lip Thickness & 12.33 & 1.84 & 10.03 & 0.81 \\
\hline Pogonion - Pogonion' & 14.07 & 2.92 & 12.00 & 1.46 \\
\hline Menton - Menton' & 11.10 & 1.47 & 8.33 & 1.12 \\
\hline Nasolabial Angle & 103.63 & 2.46 & 101.30 & $3 \cdot 56$ \\
\hline Upper Lip Angle & 9.63 & 2.27 & $7 \cdot 97$ & 1.67 \\
\hline \multicolumn{5}{|l|}{ FACIAL LENGTH } \\
\hline Nasion' - Menton' & $117 \cdot 50$ & 1.74 & $115 \cdot 40$ & 1.99 \\
\hline Upper Lip Length & 20.57 & 1.89 & 20.77 & 1.50 \\
\hline Interlabial Gap & 0.73 & 0.83 & 0.73 & 0.78 \\
\hline Lower Lip Length & 44.67 & 1.79 & 41.00 & 0.91 \\
\hline Lower $1 / 3$ of the face & $65 \cdot 53$ & 2.89 & 62.27 & 1.46 \\
\hline Overbite & 2.80 & 0.89 & 3.47 & 1.14 \\
\hline Mxi exposure & 0.73 & 0.83 & 0.73 & 0.78 \\
\hline Maxillary Height & $24 \cdot 77$ & 2.50 & 24.13 & 1.59 \\
\hline Mandibular Height & 46.00 & 1.49 & 40.50 & 1.72 \\
\hline \multicolumn{5}{|l|}{ PROJECTION TO TVL } \\
\hline Glabella & -8.30 & $3 \cdot 98$ & $-7 \cdot 43$ & 1.79 \\
\hline Nasal Projection & $14 \cdot 37$ & 1.16 & $14 \cdot 37$ & 1.13 \\
\hline Subnasale & 0.00 & 0.00 & 0.00 & 0.00 \\
\hline A Point' & -2.87 & 0.86 & -2.87 & 0.86 \\
\hline Upper Lip Anterior & 0.77 & 0.77 & 1.90 & 0.84 \\
\hline $\mathbf{M x ı}$ & $-13 \cdot 50$ & 1.14 & -12.57 & 1.87 \\
\hline
\end{tabular}




\begin{tabular}{|c|c|c|c|c|}
\hline Mdi & -15.83 & 1.23 & -14.87 & 1.68 \\
\hline Lower Lip Anterior & -3.13 & 0.73 & -1.93 & 0.74 \\
\hline B Point' & -10.77 & 1.52 & -11.53 & 1.76 \\
\hline Pogonion' & -5.0 & 1.2 & $-5 \cdot 4$ & 1.1 \\
\hline \multicolumn{5}{|l|}{ ADDITIONAL POINTS } \\
\hline Orbitale & -23.70 & 1.39 & -17.00 & 0.74 \\
\hline Cheekbone & -30.70 & $3 \cdot 70$ & -34.17 & 1.39 \\
\hline Ala of the nose & -15.87 & 1.55 & -11.80 & 1.30 \\
\hline Subpupil & -20.133 & 0.819 & -14.367 & 1.188 \\
\hline Angle of Mandible & -90.223 & 2.873 & -82.900 & 1.583 \\
\hline Chin - Throat Angle & -58.433 & 2.487 & -62.800 & 2.139 \\
\hline
\end{tabular}

Table 3. Descriptive statistics and the results of Soft Tissue Cephalometric analysis comparison between Subject males and females

as compared to the Caucasians.

The females had a more recessive chin when compared to the male subjects. These results are in accordance with

a study conducted by Shweta Raghavi4 on the central India (Malwa) female population in which it was concluded that a mild convexity of the face, recessive chin and the resulting tendency toward Class II in females is acceptable aesthetically. A study on Adolescent Kuwaitis by Rashed Al-Azemi ${ }^{12}$ concluded that the Kuwaitis have increased lip protrusion relative to the norms for white Caucasians.

A study conducted by Tancansan Uysal et al. ${ }^{7}$ in a sample of 133 Turkish adults which concluded that Turkish subjects have depressed orbital rims, cheek bones and subpupils. Conversely, in the female population, they reported a prominent orbital bone, prominent alar base and subpupil but recessive cheek bone in comparison to the Caucasians.

\section{SUMMARY AND CONCLUSION}

The present study highlights the differences between the cephalometric norms for Bihar ethnic population as against the Caucasian norms which are considered as standard.

The salient conclusions drawn from the present study are:

1) Frontal: The males and females have a short and broad face as compared to the Caucasians. Also, males have an increased facial length when compared to the females.

2) Profile: Both the subjects, male and female, have a recessive profile with recessive chin as compared to the Caucasians. The males have a more recessive profile as compared to the female subjects.

3) Lips: The males and females have thinner lips with retrusive upper and lower lips when compared to the Caucasian population. When compared to each other, males have a thicker lip with protrusive upper lip and retrusive lower lip.

4) Incisor Display: The males and females have a decreased maxillary incisor display with decreased interlabial gap when compared to the Caucasians. On comparing the male and female subjects, the incisor display was greater in males with increased interlabial gap.

5) Mid-face: The mid-face of the males and females were retrusive when compared to the Caucasians. While on comparing within the subjects, the females have a mid-face deficiency in comparison to the male subjects.

The established norms in the present study is the reference for the future treatment for the Bihar ethnic population as they are the most applicable norms for this particular population.

\section{REFERENCES}

1. Arnett GW, Bergman RT. Facial keys to orthodontic diagnosis and treatment planning. Part I. American 
Journal of Orthodontics and Dentofacial Orthopedics. 1993;103(4):299-312.

2. Arnett GW, Bergman RT. Facial keys to orthodontic diagnosis and treatment planning-part II. American Journal of Orthodontics and Dentofacial Orthopedics. 1993;103(5):395-411.

3. Arnett GW, Jelic JS, Kim J, Cummings DR, Beress A, Worley CM Jr, Chung B, Bergman R. Soft tissue cephalometric analysis: Diagnosis and treatment planning of dentofacial deformity. Am J Orthod Dentofacial Orthopedics 1999;116:239-53.

4. Kalha AS, Latif A, Govardhan SN. Soft-tissue cephalometric norms in a South Indian ethnic population. Am J Orthod Dentofacial Orthopedics 2008;133(6):876-81.

5. Richardson ER. Racial differences in dimensional traits of the human face. The Angle Orthodontist. 1980;50(4):301-11.

6. Spradley FL, Jacobs JD, Crowe DP. Assessment of the anteroposterior soft-tissue contour of the lower facial third in the ideal young adult. American journal of orthodontics. 1981;79(3):316-25.

7. Uysal T, Yagci A, Basciftci FA, Sisman Y. Standards of soft tissue Arnett analysis for surgical planning in Turkish adults. The European Journal of Orthodontics. 2009 Aug 1;31(4):449-56.

8. Basciftci FA, Uysal T, Buyukerkmen A. Determination of Holdaway soft tissue norms in
Anatolian Turkish adults. American Journal of Orthodontics and Dentofacial Orthopedics. 2003;123(4):395-400.

9. Yadav R, Gaharwar JS. Soft tissue cephalometric norms for central India population: a lateral cephalometric study. Indian Journal of Orthodontics and Dentofacial Research. 2016;2(2):83-6.

10. Shashikumar GM, Naik DP, Savakkanavar MB, Sreedhara S, Reddy SR. Hard Tissue Cephalometric Norms for Orthognathic Surgery in Karnataka Population. Journal of International Oral Health 2015;7(11):28-32.

11. Lalitha C, Kumar KG. Assessment of Arnett soft tissue cephalometric norms in Indian (Andhra) population. Orthod Cyber J. 2010.

12. Al-Azemi R, Al-Jame B, Årtun J. Lateral cephalometric norms for adolescent Kuwaitis: soft tissue measurements. Medical Principles and Practice. 2008 Apr 10;17(3):215-20.

13. Scheideman GB, Bell WH, Legan HL, Finn RA, Reisch JS. Cephalometric analysis of dentofacial normals. American journal of orthodontics. 1980;78(4):404-20.

14. Raghav S, Baheti K, Hansraj V, Rishad M, Kanungo H, Bejoy PU. Soft Tissue Cephalometric Norms for Central India (Malwa) Female Population. Journal of International Oral Health: JIOH. 2014;6(5):51-9. 